\title{
Companion cropping with potato onion enhances the disease resistance of tomato against Verticillium dahliae
}

\author{
Xuepeng $F u^{1,2}$, Xia $W^{1,3}$, Xingang Zhou ${ }^{1}$, Shouwei Liu ${ }^{1}$, Yanhui Shen ${ }^{1}$ and Fengzhi $W^{1 *}$ \\ ${ }^{1}$ Department of Horticulture, Northeast Agricultural University, Harbin, China, ${ }^{2}$ Department of Life Science and Agroforestry, \\ Qiqihar University, Qiqihar, China, ${ }^{3}$ Department of Horticulture, Heilongjiang Bayi Agricultural University, Daqing, China
}

OPEN ACCESS

Edited by:

Martin Heil,

Centro de Investigación y de Estudios Avanzados del I.P.N. - Unidad Irapuato, Mexico

Reviewed by:

Mahmut Tör

University of Worcester, UK

Karin Hage-Ahmed,

University of Natural Resources and

Life Sciences Vienna, Austria

*Correspondence:

Fengzhi Wu,

Department of Horticulture, Northeast Agricultural University, No. 59 Mucai

Street, XiangFang District, Harbin 150030, China

fzwu2006@aliyun.com

Specialty section: This article was submitted to

Plant Biotic Interactions, a section of the journal

Frontiers in Plant Science

Received: 01 July 2015

Accepted: 28 August 2015

Published: 11 September 2015

Citation:

FuX, Wu X, Zhou X, Liu S, Shen Y and

Wu $F$ (2015) Companion cropping

with potato onion enhances the disease resistance of tomato against Verticillium dahliae.

Front. Plant Sci. 6:726.

doi: 10.3389/fpls.2015.00726
Intercropping could alleviate soil-borne diseases, however, few studies focused on the immunity of the host plant induced by the interspecific interactions. To test whether or not intercropping could enhance the disease resistance of host plant, we investigated the effect of companion cropping with potato onion on tomato Verticillium wilt caused by Verticillium dahliae ( $V$. dahliae). To investigate the mechanisms, the root exudates were collected from tomato and potato onion which were grown together or separately, and were used to examine the antifungal activities against $V$. dahliae in vitro, respectively. Furthermore, RNA-seq was used to examine the expression pattern of genes related to disease resistance in tomato companied with potato onion compared to that in tomato grown alone, under the condition of infection with $V$. dahliae. The results showed that companion cropping with potato onion could alleviate the incidence and severity of tomato Verticillium wilt. The further studies revealed that the root exudates from tomato companied with potato onion significantly inhibited the mycelia growth and spore germination of $V$. dahliae. However, there were no significant effects on these two measurements for the root exudates from potato onion grown alone or from potato onion grown with tomato. RNA-seq data analysis showed the disease defense genes associated with pathogenesis-related proteins, biosynthesis of lignin, hormone metabolism and signal transduction were expressed much higher in the tomato companied with potato onion than those in the tomato grown alone, which indicated that these defense genes play important roles in tomato against $V$. dahliae infection, and meant that the disease resistance of tomato against $V$. dahliae was enhanced in the companion copping with potato onion. We proposed that companion cropping with potato onion could enhance the disease resistance of tomato against $V$. dahliae by regulating the expression of genes related to disease resistance response. This may be a potential mechanism for the management of soil-borne plant diseases in the intercropping system.

Keywords: companion cropping, disease resistance, interspecific interaction, RNA-seq, root exudates, soil-borne diseases, Verticillium dahliae 


\section{Introduction}

In modern agriculture intercropping has long been used for the increase of crop productivity and management of soilborne diseases (Boudreau, 2013; Li et al., 2014). It was widely observed that intercropping was beneficial for the management of soil-borne disease, such as inhibition of pepper Phytophthora blight in maize/pepper intercropping system (Yang et al., 2014), suppression of watermelon Fusarium wilt in rice/watermelon intercropping (Ren et al., 2008), and inhibition of soybean red crown rot in maize/soybean intercropping (Gao et al., 2014) and so on.

There are two ways, by which intercropping can suppress soil-borne disease, one of them is to decrease the attacks by pathogens, and the other one is to increase disease resistance of host plant (Ratnadass et al., 2012; Boudreau, 2013). To date, most studies focused on the less pathogen attacks, by the alteration of microenvironment and formation of "root wall" to restrict the spread of spores (Gómez-Rodriguez et al., 2003; Gao et al., 2014), or by the increase of soil microbial antagonism for pathogens (Ren et al., 2008; Fengzhi and Xingang, 2009), or/and by the direct inhibition of pathogens with root exudates from companied plants (Ren et al., 2008; Hao et al., 2010; Gao et al., 2014; Yang et al., 2014). In previous studies, the main focus was on the effects of root exudates from companied plant on the pathogen which attacks the host plant (Ren et al., 2008; Hao et al., 2010; Gao et al., 2014; Yang et al., 2014). However, whether or not the root exudates from host plant have antifungal activity on pathogen in intercropping was unknown.

In variable environments, plants have evolved defense systems to response to pathogen attacks (Chisholm et al., 2006). The potential agents in disease resistance system include pathogenesis-related proteins (PRs), defense enzymes, plant hormones and other defense related proteins (Shamrai, 2014). There were a few reports mentioned that intercropping increased the expression of PR genes, and enzymatic activity related to the defense of host plants in intercropping compared to monoculture (Gao et al., 2014; Xu et al., 2015a). However, Up to now, there was very limited knowledge regarding to the induction of disease resistance in host plant intercropped with other plant species. Whether or not the disease resistance of host plant was one of the mechanisms for the management of soil-borne plant diseases in the intercropping system was unknown.

Tomato (Solanum lycopersicum) is an important vegetable crop and cultivated worldwide. Unfortunately, tomato is a favorable host for $V$. dahliae, a soil-borne pathogen resulting in Verticillium wilt in many plant species (Klosterman et al., 2009). Potato onion (Allium cepa var. agrogatum Don.), a variant of onion, is widely cultivated in Northeast of China, and was regard as a better companion plant in terms of disease and pests management in intercropping system according to farmer's practice. In this case, it is interesting to know whether potato onion as companion plant is efficient for controlling tomato Verticillium wilt. Based on the previous studies we hypothesized (i) companion cropping with potato onion could alleviate tomato Verticillium wilt, (ii) the root exudates from potato onion and tomato have antifungal activities on $V$. dahliae growth, (iii) companion cropping with potato onion could enhance the expression of defense genes related to disease resistance against $V$. dahliae. To confirm these, we determined the effect of potato onion as a companion crop on tomato Verticillium wilt, investigated the antifungal activities of the root exudates from potato onion and tomato on $V$. dahliae growth, and investigated the expression profile of the disease resistance related genes of tomato infected with $V$. dahliae by RNA-Seq. Finally, we explored the relationship among the incidence, the effect of root exudates and gene expression on disease resistance of tomato against $V$. dahliae.

\section{Methods and Materials}

\section{Cultivation of Plants}

The tomato seeds, Qiyanaifen (susceptible to $V$. dahliae), were purchased from Qiqihar Vegetable Research Institute (Qiqihar, China). Potato onion variety Suihua, a native variety with potential allelopathy (Liu et al., 2013), was provided by Laboratory of Vegetables Physiological Ecology (harbin, China). Tomato seeds were surface sterilized with $3.8 \%$ sodium hypochlorite for $10 \mathrm{~min}$ and afterwards rinsed three times with sterile distilled water. Then germinated in a mixture of peat: perlite $(1: 1 \mathrm{v} / \mathrm{v})$. Before transplanting, the tomato seedlings were cultivated in the greenhouse located in the Experimental Center of the Northeast Agricultural University, Harbin, China $\left(45^{\circ} 41^{\prime} \mathrm{N}, 126^{\circ} 37^{\prime} \mathrm{E}\right)$. Potato onion was stored at $4^{\circ} \mathrm{C}$ before planting.

\section{Fungal Culture}

The $V$. dahliae race 1 (Vd1) was provided by Tomato Breeding Center of Northeast Agricultural University (harbin, China). Spore suspensions were prepared and gave a final concentration of $1.0 \times 10^{7}$ spores $\cdot \mathrm{mL}^{-1}$ sterile $0.5 \%$ gelatin solution (Pegg and Street, 1984; Dobinson et al., 1996). The pathogenicity of Vd1 was tested by dipping the tomato roots into a spore suspension $(1.0 \times$ $10^{7} \mathrm{~mL}^{-1}$ ) and replanted in autoclaved soil in our preliminary trial (Orenstein et al., 1989). After the plants were treated for 15 days, the symptoms of Verticillium wilt were observed.

\section{Determination of the Incidence and Symptom Scoring of Tomato Verticillium Wilt}

The pot culture experiments were conducted in the greenhouse to test the effect of companion cropping with potato onion on tomato Verticillium wilt in 2013 and 2014, respectively. The tomato seedlings with four true-leaf were transplanted into pots (17 cm diam, $19 \mathrm{~cm}$ height) filled with autoclaved field soils according to the methods described by van Wees et al. (2000). The soils were autoclaved twice for $20 \mathrm{~min}$ with a $24 \mathrm{~h}$ interval, thus the microbes in the soils were eliminated (examined by plate cultivation method, data unshown). The pot experiments were conducted with three blocks, each containing two cropping treatments. One was tomato/potato onion companion cropping, which meant one tomato seedling grew with two potato onion bulbs with the distance of $10 \mathrm{~cm}$ between tomato and potato onion bulbs, as TC treatment (TC). The other one was tomato monoculture, which meant one tomato seedling grew alone 
(without potato onion) in the pot, served as TM treatment (TM). Each treatment contained 10 pots (10 TC or $10 \mathrm{TM})$. The arrangement of the pots was randomized completely. Before planted into the pot, the roots of tomato seedlings and potato onion bulbs were cleaned with tap water first, then washed with autoclaved water for three times. Autoclaved water was applied throughout the experiment. The weeds were removed manually.

Twenty days after transplanting, the seedlings of both treatments were inoculated with $20 \mathrm{~mL}$ spore suspension $(1 \times$ $10^{7}$ spores $\cdot \mathrm{mL}^{-1}$ ) solution of $\mathrm{Vd} 1$ by pouring into rhizosphere of each tomato seedling (Gao et al., 2014). The incidence and the symptoms scoring of Verticillium wilt were observed and calculated from 10 to 30 days after the inoculation (DAI), with a 3 days interval. The incidence was defined as the percentage of tomato seedlings with disease symptoms in all treated seedlings in each treatment. The symptoms scoring was evaluated by $0-$ 5 scale based on the numbers of leaves with disease symptoms (Shittu et al., 2009), that is: 0, healthy; 0.5, premature loss of both cotyledons; 1.0, yellowing and flaccidity of the first leaf; 2.0 , lower $40 \%$ of leaves infected; 3, lower $60 \%$ of leaves infected; 4 , lower $80 \%$ of leaves infected; 5 , plant dead. Stunting $(>2.5 \mathrm{~cm}$ shorter than control) contributes an additional 0.5 to the disease score of each plant. The incidence and the symptoms scoring were evaluated independently by two observers and averaged.

\section{Test of Antifungal Activities of Root Exudates in vitro}

The tomato seedlings with four true leaves were cultivated in a plant growth chamber at $25^{\circ} \mathrm{C}$ with a photoperiod of $16 \mathrm{~h}$ light $/ 8 \mathrm{~h}$ dark. There were four treatments in this study, which were TC and TM (same as greenhouse studies), OC (potato onion grown with tomato) and OM (potato onion grown alone). The inoculation was the same as greenhouse studies mentioned above at 20th after companied with potato onion. The collection of root exudates was carried out according to the method reported previously (Ren et al., 2008; Li et al., 2013) at 7 DAI with a little modification. Briefly, roots of tomato and potato onion in different treatments were gently collected from soils and washed with tap water, then washed with autoclaved water. Cleaned roots were completely submerged in a beaker with $200 \mathrm{~mL}$ of autoclaved deionized water, and were placed in a plant growth chamber for $6 \mathrm{~h}$ at $24^{\circ} \mathrm{C}$ with light. During the collections, each beaker contained 6 seedlings and covered by tinfoil to avoid contamination and light. Thereafter, the exudates solution were concentrated by freeze-dry and adjusted with autoclaved deionized water to $1 \mathrm{~g}$ fresh weight of root per $10 \mathrm{~mL}$ exudate solution ( $1 \mathrm{~g} \mathrm{FW} \cdot 10 \mathrm{~mL}^{-1}$ ) (Hao et al., 2010; Li et al., 2013). The root exudates were filtered through a $0.22 \mu \mathrm{m}$ millipore filters and stored at $-20^{\circ} \mathrm{C}$ up to further investigation.

Poison food technique was used to measure the antifungal activity of the root exudates in vitro (Gao et al., 2014). Briefly, $2 \mathrm{~mL}$ root exudates of each treatment (OM, OC, TM, TC) were added to Potato Dextrose Agar medium (PDA) (Robb et al., 2009) before it solidified, to yield a total volume of $20 \mathrm{~mL}$ per
Petri dish $(90 \times 15 \mathrm{~mm})$. A mycelia disc $(5 \mathrm{~mm}$ in diameter $)$ was taken out from 10 days-old culture of $\mathrm{Vd} 1$ and placed in the center of test Petri dish to observe the growth of mycelia. In order to evaluate the inhibition of the root exudates, the colony diameters were measured using a ruler in three directions on each plate after incubation for 6 days. For determination of spore germination, the spore suspension was diluted to about $1 \times 10^{3}$ spores $\cdot \mathrm{mL}^{-1}$ in autoclaved distilled water. Aliquots of $100 \mu \mathrm{L}$ diluted suspension were spread on the Petri dish. The colonies, which were generated by single germinated spore, respectively, were counted to express the germinated spores after 3 days of incubation. In both measurements $2 \mathrm{~mL}$ autoclaved deionized water was used in the control (CK) and the fungus were incubated at $23^{\circ} \mathrm{C}$ in the dark (Robb et al., 2009). Each treatment had five replicates.

\section{Analysis of Differently Expressed Genes (DEGs) in Tomato Roots by RNA-seq Plant Material, Pathogen Inoculation, and Sample Collection}

The procedure used for preparing the tomato seedlings was the same as the one for the collection of root exudates. Briefly, this experiment had two treatments, TM and TC. The roots of tomato plants were collected at $3 \mathrm{DAI}$. Three samples were prepared for each treatment, respectively, and each sample was pooled from the roots of 5 seedlings. The samples were named TM1, TM2, TM3, and TC1, TC2, TC3, flash frozen in liquid nitrogen, and stored at $-80^{\circ} \mathrm{C}$ until using for the RNA extraction and RNA-seq library preparation.

\section{RNA-seq Library Preparation and Sequencing}

Total RNA was extracted from different samples (TM1, TM2, $\mathrm{TM} 3$, and TC1, TC2, TC3), respectively and treated with DNase I to degrade any possible DNA contamination using RNAprep pure Plant Kit (TIANGEN, China) as described by the manufacturer. RNA was quantified using Agilent 2100 Bioanalyzer (Agilent Technologies, USA), the quality and integrity were assessed by NanoDrop. Quality, quantity and integrity of total RNA from different samples were qualified for RNA-Seq library preparation and sequencing (Additional file 1: Table S1).

RNA-Seq library preparation and sequencing were conducted in BGI Tech (Shenzhen, China). Stepwise below, the mRNA was enriched by using the oligo (dT) magnetic beads, then fragmented into short fragments and mixed with the fragmentation buffer. The first strand of cDNA was synthesized by using random hexamer-primer, and the second strand by addition of Buffer, dNTPs, RNase $\mathrm{H}$ and DNA polymerase I. Magnetic beads were used to purify the double strand cDNA. End reparation and $3^{\prime}$ - end single nucleotide A (adenine) addition is then performed. At last, sequencing adaptors were ligated to the fragments. The fragments were enriched by PCR amplification. The library products were qualified and quantified by Agilent 2100 Bioanaylzer and ABI StepOnePlus Real-Time PCR System, followed with sequencing by Illumina HiSeq $^{\mathrm{TM}} 2000$. 


\section{Analysis of Illumina Sequencing Results}

Primary sequencing data (called raw reads) produced by Illumina HiSeq $^{\text {TM }} 2000$ were cleaned by discarding reads with adapters and reads in which unknown bases are more than $10 \%$. Low quality reads (sequencing quality is no more than 5) were removed as well. BWA ( $\mathrm{Li}$ and Durbin, 2009) was used to map clean reads to tomato genome reference, and Bowtie (Langmead et al., 2009) to gene reference using the default parameters, respectively. Genes expression levels in terms of transcripts were quantified by RSEM (RNASeq by Expectation Maximization) and FPKM (Fragment Per Kilobase of exon model per Million mapped reads) method (Li and Dewey, 2011). The FPKM between the biological replications was analyzed by Pearson correlation. In our study, the Pearson coefficient of gene expression in different replications was more than 0.85 , indicating the consistency between the replicates (Additional file 2: Figure S1). According to the studies by Tarazonz et al., the Noiseq method was selected to screen differential expressed genes (DEGs) between group TM and $\mathrm{TC}$, with diverge probability $\left(\mathrm{P}_{\mathrm{NOI}}\right) \geq 0.8$ and the absolute value of fold change $\geq 2\left(\log _{2}^{\text {Ratio }} \geq 1\right)$ as the threshold value (Tarazona et al., 2011).The expression patter analysis of DEGs is performed with cluster and java Treeview software. WEGO was used to classify GO function (Ye et al., 2006). Kyoto Encyclopedia of Genes and Genomes (KEGG), the major public pathwayrelated database, is used to perform pathway enrichment analysis of DEGs with $\mathrm{Q} \leq 0.05$ as significantly enriched threshold (Kanehisa et al., 2008).

\section{Verification of RNA-seq Results by Quantitative Real-time PCR (qRT-PCR)}

Twelve genes were randomly chosen for verification of RNA-seq results by qRT-PCR. Gene-specific primers were designed using Primer 5.0 software and synthesized by Sangon Biotech Company (Shanghai, China). The genes and primer sequences were listed in Additional file 3: Table S2. The same RNA samples used for RNA-seq library preparation and sequencing were used for the qRT-PCR validation. First-strand cDNA was synthesized with $2 \mu \mathrm{g}$ of total RNA for reverse transcribing in a $20 \mu \mathrm{L}$ reaction system using the TIANScript RT Kit. The qRT-PCR reactions were performed on iQ5 Multicolor Real-Time PCR Detection System (BIO-RAD, USA), using RealmasterMix (SYBR Green) (TIANGEN, China) according to the manufacturer's protocol. Each sample was analyzed with three replicates. The mRNA expression levels of the target genes were normalized relative to the expression of tomato Actin gene (Løvdal and Lillo, 2009; Yang et al., 2015) and calculated using the $2^{-\Delta \Delta C t}$ method.

\section{Statistical Analysis}

In each experiment, the treatments were arranged in triplicate. Every experiment was conducted twice independently except RNA-seq analysis. SPSS 16.0 analysis software (SPSS Inc., USA) was used for statistical analysis. Differences between both treatment groups were tested by the independent sample $t$-test at $p=0.05$ level. Analysis of variance (ANOVA) was performed among different treated groups, and the means of different treatments were compared by Tukey's tests at $p=0.05$ level. All data were expressed as mean \pm standard error.
Results

\section{Effect of Companion Cropping with Potato Onion on the Incidence and Disease Severity of Tomato Verticillium Wilt}

The results regarding to the disease incidence and disease symptoms score of tomato were shown in Figure 1. Compared to TM (tomato monoculture), the disease incidences in TC (tomato companied with potato onion) were decreased by 24.97 and $27.13 \%$ in 2013 , by 35.58 and $19.83 \%$ in 2014 at 18 and 28 DAI, respectively (Figures 1A,B). Similarly, the disease symptoms scores of tomato were significantly declined $(p \leq 0.05)$ in TC compared to TM at all observed stages except 18 DAI in 2013, in which disease symptoms scores was also lower, but not significant (Figures 1C,D).

\section{Effect of Root Exudates on Vd1 Mycelia Growth and Spore Germination}

The whole process for antifungal activities of root exudates was conducted twice independently and the results were shown in Figure 2. In comparison with $\mathrm{TM}$ and $\mathrm{CK}$ (without root exudates), the root exudates from TC significantly inhibited Vd1 mycelia growth in terms of colony diameter $(p \leq$ 0.05) (Figures $2 \mathrm{~A}, \mathrm{C}$ ) with the concentration of $1 \mathrm{~g} \mathrm{FW} \cdot 10 \mathrm{~mL}$ 1. However, when the concentration was decreased to $1 \mathrm{~g}$ FW. $20 \mathrm{~mL}-1$, the root exudates from TC had no significant inhibition effect on the $\mathrm{Vd} 1$ mycelia growth. In contrast, the root exudates from both $\mathrm{OM}$ (potato onion grown alone) and OC (potato grown with tomato) had no significant effect on the mycelia growth at any condition (Figure 2B). Effects of root exudates on $\mathrm{Vd} 1$ spore germination were similar to those on $\mathrm{Vd} 1$ mycelia growth (Figure 2D).

\section{Expression Profile Analysis of Tomato Root Exposed To Vd1 for 3 days by RNA-seq RNA-seq Library Sequencing and Sequencing Quality Evaluation}

Six RNA-seq libraries (TM1, TM2, TM3, and TC1, TC2, TC3) were sequenced and the raw reads were deposited in the NCBI Sequence Read Archive database (Accession SRP057823). After removing the low quality reads, the total number of clean reads in each library ranged from 12.16 to 12.17 million, accounted for 99.78 to $99.87 \%$ of total reads (Additional file 4: Figure S2). Base Composition and Quality Distribution of clean data (Additional file 5: Figure S3), Sequencing Saturation Analysis (Additional file 6: Figure S4), as well as Reads Distribution on Gene (Additional file 7: Figure S5) were used for sequence quality assessment. The results showed the sequencing of all the samples had good quality for further analysis.

\section{Differential Expressed Genes (DEGs) Analysis and Verification of RNA-seq Results}

The reads from each sample were aligned to the Solanum lycopersicum reference genome, the alignment data and assembly statistics were listed in Table 1. DEGs were screened by Noiseq method, because it had a good performance (Tarazona et al., 2011 , with the probability $\left(\mathrm{P}_{\mathrm{NOI}}\right)=0.8$ as threshold value as 
A
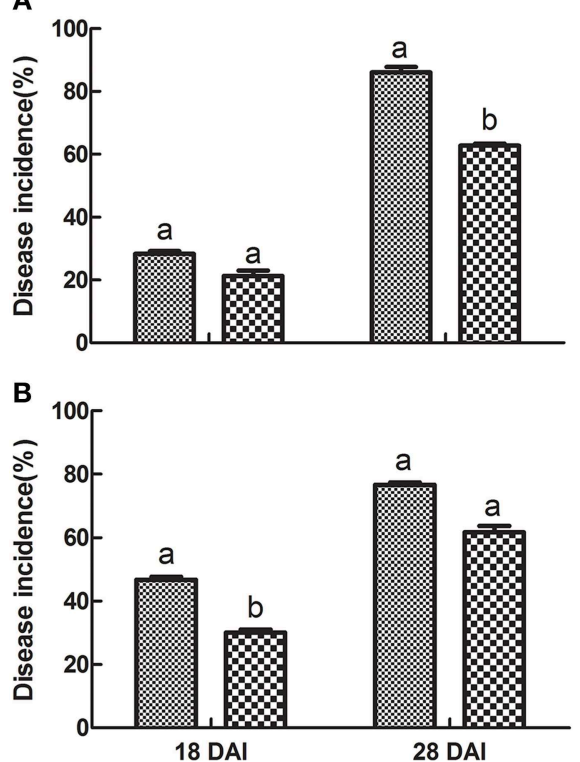

C

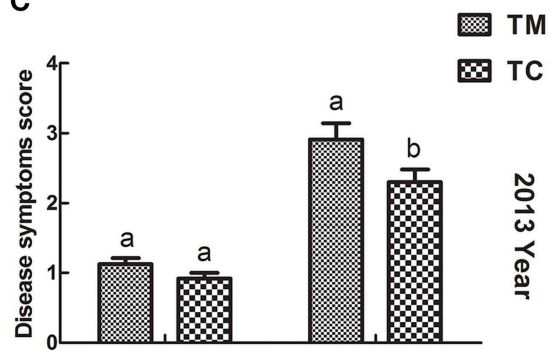

D

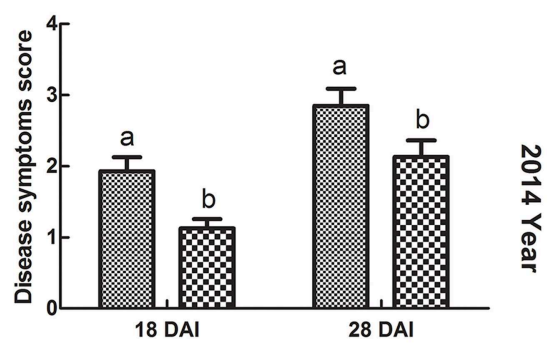

FIGURE 1 | Disease incidence and disease symptoms score of tomato inoculated with Vd1. (A,B) Disease incidence of tomato in 2013 and 2014, respectively. (C,D) Disease symptoms score in 2013 and 2014, respectively. 18 DAl and 28 DAT indicate 18 and 28 days after infected by Vd1, respectively. Data were the means of three replicates with standards errors shown by vertical bars. The different small letters above the bars represent the significance between two groups of mean values at a lever of $p=0.05$ according to independent sample $t$-test.
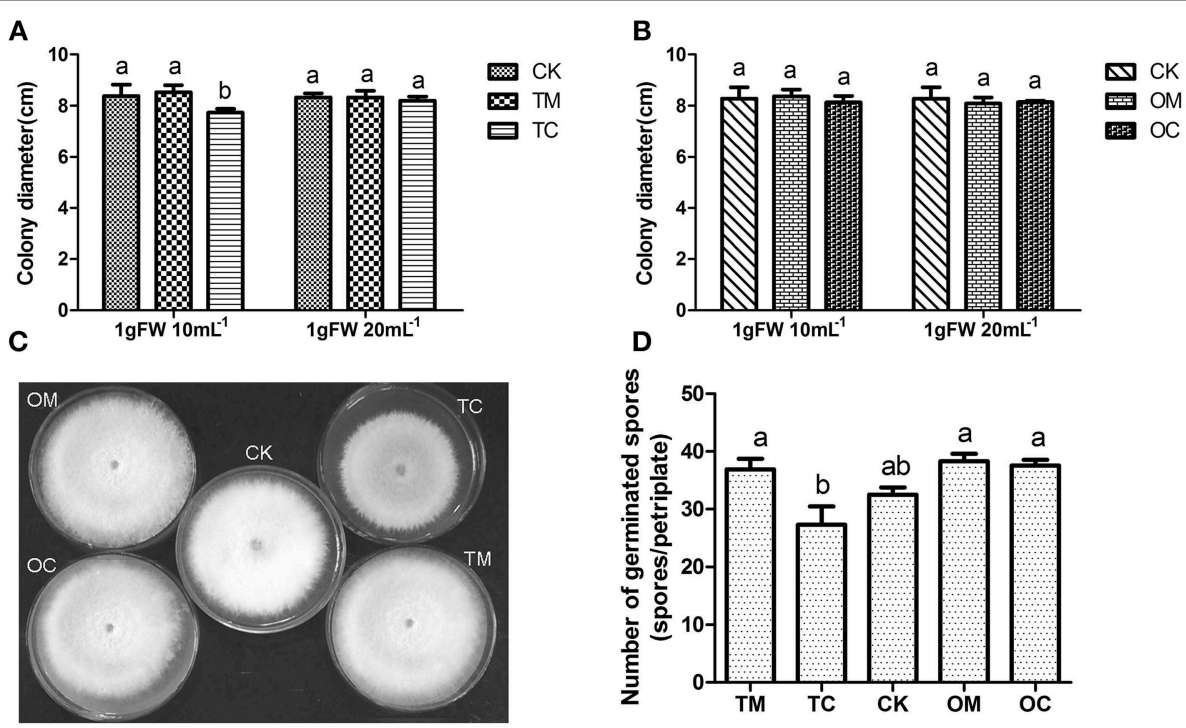

FIGURE 2 | Effect of root exudates on the mycelia growth and spore germination of Vd1. (A) Effect of root exudates from tomatoes on Vd1 mycelia growth (colony diameter). (B) Effect of root exudates from potato onions on Vd1 mycelia growth (colony diameter). (C) Effect of root exudates from tomatoes and potato onions on Vd1 mycelia growth (colony diameter) at a concentration of $1 \mathrm{gFW} \cdot 10 \mathrm{~mL}^{-1}$. (D) Effect of root exudates from tomatoes and potato onions on Vd1 spore germination at a concentration of $1 \mathrm{~g} \mathrm{FW} \cdot 10 \mathrm{~mL}^{-1}$. Data are the means of five replicates with standards errors shown by vertical bars. The different small letters above the bars represent among different groups according to Tukey's tests at $p=0.05$ level.

described in many reports (Tarazona et al., 2011; Zheng and Moriyama, 2013; Xu et al., 2015b). The results from Noiseq analysis showed there were total 369 DEGs between TM and TC, among which 307 DEGs were up-regulated and 62 DEGs were down-regulated in terms of expression pattern, indicating the upregulated genes were far more than down-regulated (Figure 3). All DEGs were listed in Additional file 8: Table S3. But we found the $\log 2$ values of the DEGs screened by Noiseq method 
TABLE 1 | Alignment statistics result with reference genome for all samples.

\begin{tabular}{|c|c|c|c|c|c|c|c|c|}
\hline Sample & $\begin{array}{l}\text { Total } \\
\text { reads }\end{array}$ & $\begin{array}{c}\text { Total base } \\
\text { pairs }\end{array}$ & $\begin{array}{c}\text { Total mapped } \\
\text { reads/ }\end{array}$ & $\begin{array}{c}\text { Perfect match/ } \\
\text { match/ }\end{array}$ & Mismatch/ & Unique match/ & $\begin{array}{c}\text { Multi-position } \\
\text { match/ }\end{array}$ & $\begin{array}{l}\text { Total unmapped } \\
\text { reads/ }\end{array}$ \\
\hline TC1 & 12173342 & 596493758 & $10419039(85.59 \%)^{\star}$ & 8842098 (72.63\%) & 1576941 (12.95\%) & 10026087 (82.36\%) & 392952 (3.23\%) & 1754303 (14.41\%) \\
\hline TC2 & 12175372 & 596593228 & 10291852 (84.53\%) & 8683647 (71.32\%) & 1608205 (13.21\%) & 9910113 (81.39\%) & 381739 (3.14\%) & $1883520(15.47 \%)$ \\
\hline TC3 & 12175309 & 596590141 & 10280870 (84.44\%) & 8671568 (71.22\%) & 1609302 (13.22\%) & 9888545 (81.22\%) & 392325 (3.22\%) & 1894439 (15.56\%) \\
\hline TM1 & 12172555 & 596455195 & 10479406 (86.09\%) & 9031982 (74.20\%) & 1447424 (11.89\%) & 10118908 (83.13\%) & 360498 (2.96\%) & 1693149 (13.91\%) \\
\hline TM2 & 12165484 & 596108716 & 10357756 (85.14\%) & 8719061 (71.67\%) & 1638695 (13.47\%) & 9885908 (81.26\%) & $471848(3.88 \%)$ & $1807728(14.86 \%)$ \\
\hline TM3 & 12175211 & 596585339 & 10470208 (86.00\%) & 8843302 (72.63\%) & 1626906 (13.36\%) & 10065455 (82.67\%) & 404753 (3.32\%) & 1705003 (14.00\%) \\
\hline
\end{tabular}

*Indicates percentages in total reads.

\section{Gene Expression Level (TM-VS-TC)}

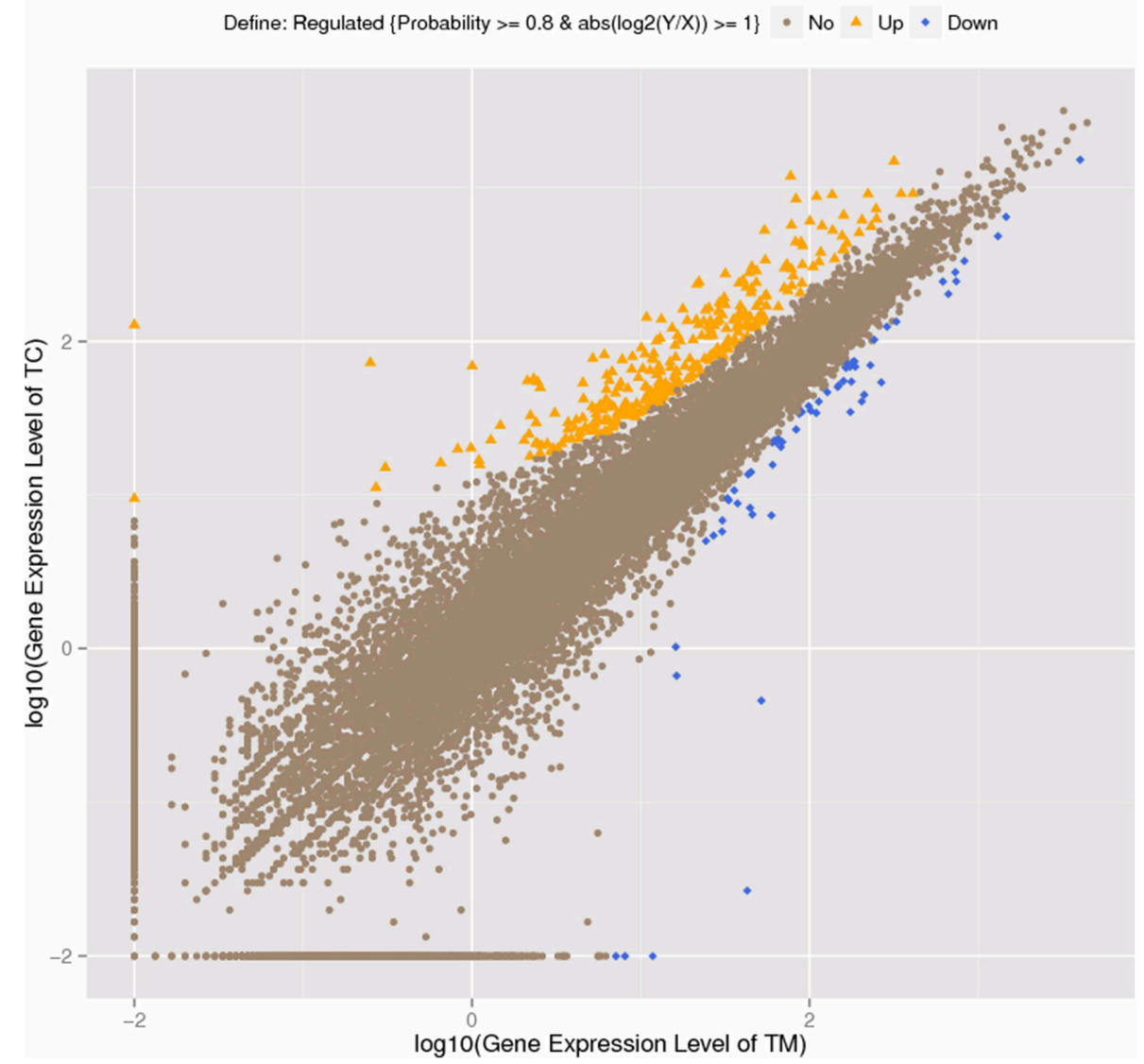

FIGURE 3 | Gene expression level in TC compared to TM.

were not very high (Additional file 8: Table S3). To confirm the RNA-seq results, the expression of 12 genes which contain eight up-regulated genes, two down-regulated genes and two genes without variation were quantified by qRT-PCR. The results of the qRT-PCR analysis were consistent to those obtained by RNAseq analysis except Aquaporin gene (Solyc12g044330.1.1), which was no variation between groups in qRT-PCR result, while it was down-regulated in RNA-seq result (Additional file 9: Table S4). This result indicated the Illumina sequencing in our study was of high reliability. Additionally, the Log2 values were not much difference between the two methods (Additional file 9: Table S4), indicating the DEGs screened by Noiseq method was of high reliability, too.

\section{GO Analysis for DEGs}

$\mathrm{GO}$ analysis was used to determine the functions of all DEGs. The DEGs were categorized into three groups as shown in Figure 4. In the cellular component group; cell, cell-part, organelle, 


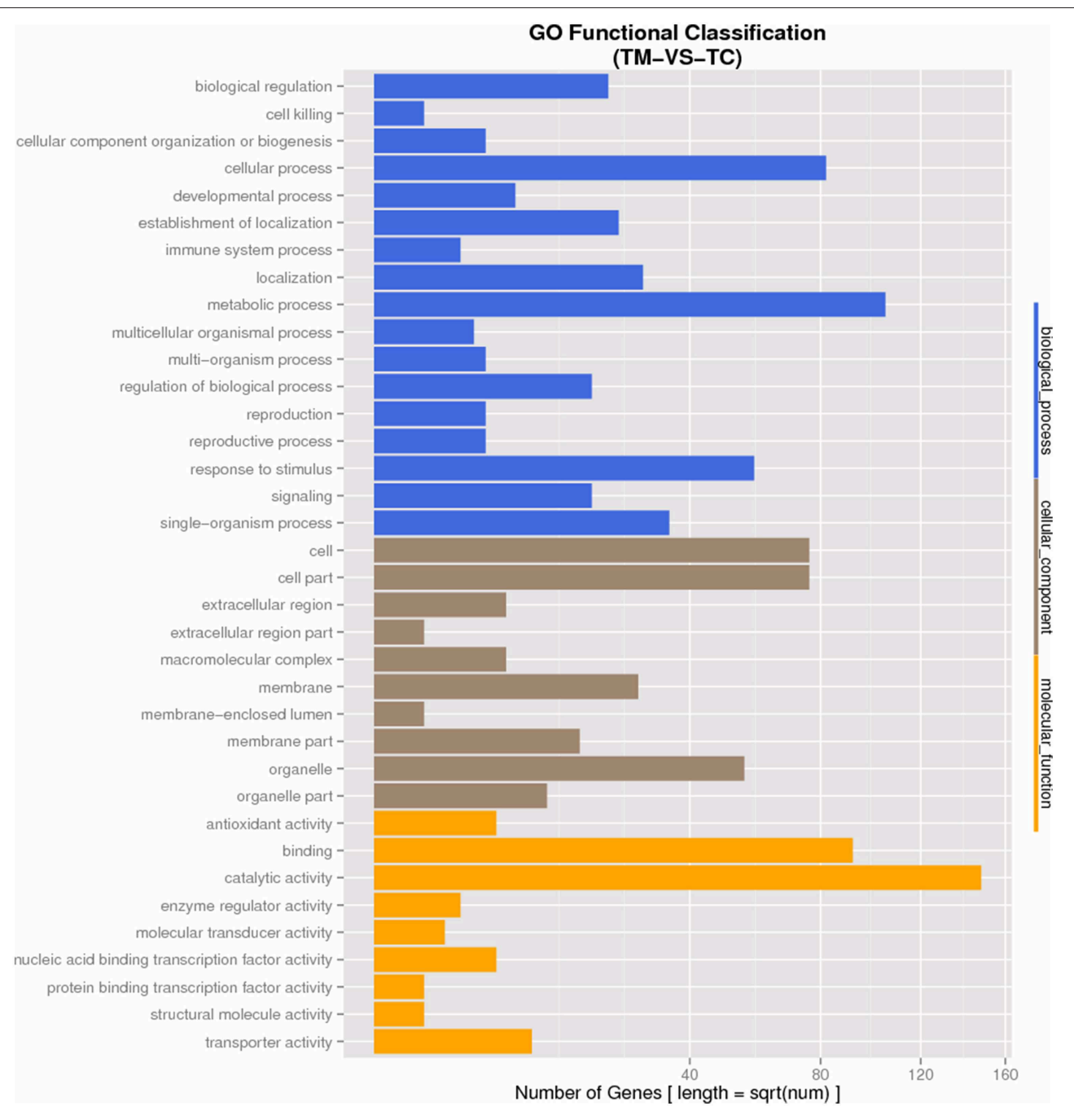

FIGURE 4 | GO Functional Classification of DEGs.

membrane-part were the most abundant GO terms induced by TC. Within the biological process categories, metabolic process, cellular process, response to stimulus, biological regulation, localization, regulation of biological process and signaling were dominant terms. The metabolic process, response to stimulus, regulation of biological process and signaling were all involved in the response to the infection of pathogen, indicating the pathogen response related genes were induced in TC. In terms of molecular function, catalytic activity and binging were most GO terms, followed by antioxidant activity, transporter activity, and nucleic acid binding transcription factor activity. All the enriched molecular function categories were involved in the metabolism and transcriptional regulation process in tomato roots exposed to Vd1.

\section{Pathway Enrichment Analysis for DEGs}

The 369 DEGs sequences were mapped to the reference canonical pathways in KEGG. A total of 211 DEGs could be annotated in KEGG database and assigned to 65 KEGG pathways. The metabolic pathway was the biggest term and contained 70 DEGs occupying 33.18\%, followed by Biosynthesis of secondary metabolites (54, 25.59\%), Phenylpropanoid biosynthesis (18, $8.53 \%)$, Zeatin biosynthesis (18, 8.53\%), Glutathione metabolism (17, 8.06\%), Plant hormone signal transduction (17, 8.06\%). The summary of significantly enriched KEGG pathways in DEGs was shown in Additional file 10: Table S5, and top 20 enriched KEGG pathways were shown in Table 2.

\section{DEGs Involved in the Functions of Disease Defense}

Transcriptional levels of the genes coding for Phenylalanine ammonia-lyase (PAL), Trans-cinnamate 4-monooxygenase, Ferulate-5-hydroxylase, 4-coumarate-CoA Ligase-like protein, Laccase, and Peroxidase 3 were much higher in TC than the ones in TM (Table 3), especially for Phenylalanine ammonia-lyase gene (Solyc03g071870.1.1) and Laccase gene (Solyc04g072280.2.1), they were 20 and 22 times higher in TC than the ones in TM, respectively. It was notable that all these genes were involved in the biosynthesis of lignin. 
TABLE 2 | Top 20 enriched KEGG pathways.

\begin{tabular}{lcc}
\hline Pathway & $\begin{array}{c}\text { DEGs with pathway } \\
\text { annotation }\end{array}$ & Pathway ID \\
\hline Metabolic pathways & $70\left(33.18 \%{ }^{*}\right)$ & ko01100 \\
Biosynthesis of secondary & $54(25.59 \%)$ & ko01110 \\
metabolites & $18(8.53 \%)$ & ko00908 \\
Zeatin biosynthesis & $18(8.53 \%)$ & ko00940 \\
Phenylpropanoid biosynthesis & $17(8.06 \%)$ & ko00480 \\
Glutathione metabolism & $17(8.06 \%)$ & ko04075 \\
Plant hormone signal transduction & $10(4.74 \%)$ & ko00360 \\
Phenylalanine metabolism & $10(4.74 \%)$ & ko04626 \\
Plant-pathogen interaction & $9(4.27 \%)$ & ko00944 \\
Flavone and flavonol biosynthesis & $9(4.27 \%)$ & ko00941 \\
Flavonoid biosynthesis & $8(3.79 \%)$ & ko00270 \\
Cysteine and methionine metabolism & $8(3.79 \%)$ & ko00500 \\
Starch and sucrose metabolism & $7(3.32 \%)$ & ko00945 \\
Stilbenoid, diarylheptanoid and & & \\
gingerol biosynthesis & $6(2.84 \%)$ & ko00402 \\
Benzoxazinoid biosynthesis & $6(2.84 \%)$ & ko00190 \\
Oxidative phosphorylation & $5(2.37 \%)$ & ko00460 \\
Cyanoamino acid metabolism & $5(2.37 \%)$ & ko00073 \\
Cutin, suberine, and wax biosynthesis & $5(2.37 \%)$ & ko00053 \\
Ascorbate and aldarate metabolism & $5(2.37 \%)$ & ko00906 \\
Carotenoid biosynthesis & $5(2.37 \%)$ & ko02010 \\
ABC transporters & & \\
\hline
\end{tabular}

*/ndicates the percentage of the total DEGs.

Secondly, the transcriptional levels of some proteins, which were related in antifungal activities, were increased significantly, they were listed in Table 4. The expression of gene coding Wall-associated receptor kinase-like 20 (Solyc01g100090.1.1) was only observed in TC. The transcripts of genes coding pathogenesis-related protein STH-2-like (Solycg05g054380.1.1), Pathogenesis-related protein PR-1 (Solycg006700.1.1), Kunitz trypsin inhibitor (Solyc03g098740.1.1), and Kunitz-type protease inhibitor (Solyc03g019690.1.1) were higher more than 10 times in TC compared to the ones in TM.

Finally, the expressions of genes related to hormone metabolism and signaling pathways were increased by the companion cropping with potato onion (Table 5). The expressions of genes coding 1-aminocyclopropane-1-carboxylate oxidase (Solycg026650.2.1 and Solyc01g095080.2.1), and Phenylalanine ammonia-lyase (Solyc03g071870.1.1 and and Solyc10g011930.1.1) were higher more than 10 times in TC compared to the ones in TM.

\section{Discussion}

\section{Companion Cropping with Potato Onion Alleviated the Disease Development of Tomato Verticillium Wilt}

In this study, the results showed that companion cropping with potato onion could alleviate disease development of tomato Verticillium wilt based on the disease incidence and disease symptoms score when tomato was companied with potato onion (Figure 1). These were consistent with the previous studies (Ren et al., 2008; Gao et al., 2014; Yang et al., 2014), which demonstrated intercropping could suppress soil-borne disease. However, the field study is needed further to confirm the phenomenon, because some other factors may affect the results. As Gao et al., and Yang et al., reported, the horizontal distance between two plant species could be involved in the efficiency of disease controlling (Gao et al., 2014; Yang et al., 2014).

In field, some other factors could affect the incidence and disease severity of soil-borne disease, such as the alteration of microenvironment and form of "root wall" (Gómez-Rodriguez et al., 2003; Gao et al., 2014), or/and direct inhibition of pathogens with root exudates from intercropped plants (Ren et al., 2008; Hao et al., 2010; Gao et al., 2014; Yang et al., 2014). These factors could decrease the number of pathogens which attack plants. But in our studies, each tomato seedling was inoculated artificially with the same pathogen, therefore, the effects of these other factors could be negligible, indicating the efficiency of disease controlling in our study was mainly depended on the disease resistance of tomato.

\section{Companion Cropping with Potato Onion Could Induce the Antifungal Activity of Tomato Root Exudates on the Inhibition of V. dahliae Growth}

Previous studies indicated that the antifungal activity of root exudates may inhibit the growth of soil-borne pathogens in intercropping system. However, all of the researches were focused on the effects of the root exudates from companion plants on the pathogens (Ren et al., 2008; Hao et al., 2010; Gao et al., 2014). Interestingly, in this study, the root exudates from the companion plant (potato onion) had no effects on $V$. dahliae, instead the root exudates from host plant (tomato) did (Figure 2). The results obtained from our study suggest that the tomato was induced to produce an antifungal activity to defense the pathogens when it was companied with potato onion. This was similar to the study reported by Gao et al., who demonstrated that the root exudates of maize/soybean intercropped plants inhibited the growth of Cylindrocladium parasiticum (Gao et al., 2014). However, in their study, which plant generated the antifungal substance remained unknown. In our study we demonstrated that the antifungal activity of root exudates came from tomato, which was the host plant instead of the companion plant. To our knowledge, our result is the first report to demonstrate that intercropping could induce the antifungal activity of root exudates from the host plant.

Interestingly, our results posed a new scientific problem. That was what induced the antifungal activity of root exudates from host plant (tomato)? As Hage-Ahmed et al., have demonstrated the root exudates from the tomatoes which were inoculated with arbuscular mycorrhizal fungi (AMF) and Fusarium oxysporum f.sp. lycopersici (Fol) could inhibit the spore germination of Fol, rather than those inoculated with AMF or Fol individually (HageAhmed et al., 2013). It suggested that the interactions of tomatoAMF- Fol induced the generation of antifungal substances for the defense to pathogens. In our study, it was the root exudates from tomato which was companied with potato onion, together 
TABLE 3 | Expression patterns of DEGs related to biosynthesis of lignin.

\begin{tabular}{|c|c|c|c|}
\hline Gene ID & Ratio of FPKM (TC/TM) & Probability & Description \\
\hline Solyc03g071870.1.1 & 20.49 & 0.844008772 & Phenylalanine ammonia-lyase \\
\hline Solyc10g011920.1.1 & 5.99 & 0.863015339 & Phenylalanine ammonia-lyase \\
\hline Solyc10g011930.1.1 & 10.15 & 0.906945967 & Phenylalanine ammonia-lyase \\
\hline Solyc00g282510.1.1 & 7.30 & 0.898564424 & Phenylalanine ammonia-lyase \\
\hline Solyc09g007910.2.1 & 3.38 & 0.814515824 & Phenylalanine ammonia-lyase \\
\hline Solyc05g047530.2.1 & 5.34 & 0.810640148 & Trans-cinnamate 4-monooxygenase \\
\hline Solyc00g247300.2.1 & 2.97 & 0.831442762 & Ferulate-5-hydroxylase \\
\hline Solyc06g035960.2.1 & 6.41 & 0.873035379 & 4-coumarate-CoA ligase-like protein \\
\hline Solyc03g097500.2.1 & 5.37 & 0.863885003 & Hydroxycinnamoyl CoA shikimate \\
\hline Solyc03g097500.2.1 & 8.04 & 0.886628603 & Hydroxycinnamoyl transferase \\
\hline Solyc04g078660.1.1 & 3.39 & 0.822122232 & Hydroxycinnamoyl transferase \\
\hline Solyc01g107080.2.1 & 22.22 & 0.897934233 & Laccase \\
\hline Solyc04g072280.2.1 & 4.18 & 0.800374334 & Laccase \\
\hline Solyc06g050530.2.1 & 2.56 & 0.800078144 & Laccase 1a \\
\hline Solyc04g054690.2.1 & 2.69 & 0.810375468 & Laccase-13 \\
\hline Solyc06g082240.2.1 & 0.40 & 0.818530142 & Peroxidase \\
\hline Solyc06g082420.2.1 & 7.75 & 0.864389156 & Peroxidase 3 \\
\hline Solyc02g087070.2.1 & 3.82 & 0.829369431 & Peroxidase family protein \\
\hline
\end{tabular}

Probability $\geq 0.8$ and absolute value of Ratio $\geq 2$ as the threshold to judge the significance of gene expression difference. FPKM represents the expression level.

with the infection by $V$. dahliae, was induced to generate the antifungal activity against $V$. dahliae. However, it was unknown that this antifungal activity of root exudates was generated before or after the infection by $V$. dahliae? In other words, the problem on which this antifungal activity was induced by the interactions of plant (tomato)-plant (potato onion) or plant (tomato)-plant (potato onion)-pathogen ( $V$. dahliae) deserved further investigation.

\section{Companion Cropping with Potato Onion Could Enhance the Expression of Genes Involved in Disease Resistance of Tomato Against V. dahliae}

The generation of antifungal activity in the root exudates of tomato increased disease resistance of tomato. To explore how the disease resistance of tomato was enhanced in transcriptional level, RNA-Seq was employed. The results showed that the expressions of many genes were changed in the tomato companioned with potato onion. By further analysis of KEGG, it was found that the most affected genes were the genes that were involved in metabolic pathway and biosynthesis of secondary metabolites in the tomato (Table 2), which suggest that the metabolism was enhanced in the root of tomato grown with potato onion. It was deduced that the antifungal activity was produced by secondary metabolite(s), and the metabolite(s) was generated by the genes, which were involved in the metabolism pathway.

The DEGs analysis showed that the expressions of genes involved in disease defense were increased in the roots of tomato companied with potato onion. Without a doubt, the increases on these gene expressions were beneficial to the disease resistance of tomato. Lignin was considered to function as a physical barrier against infection of pathogens
(Underwood, 2012). The expression levels of genes involved in biosynthesis of lignin were higher in roots of tomato companied with potato onion compared to that in tomato grown alone (Table 3). This was consistent with previous studies in the watermelon challenged with Fusarium oxysporum f.sp. niveum and in the banana infected with Fusariu $m$ oxysporum f.sp. cubense Tropical Race 4 (Lü et al., 2011; Bai et al., 2013).

Pathogenesis-related proteins (PRs) are important inducible defense-related proteins upon infection with various pathogens (van Loon et al., 2006). In our study the expressions of genes coding PR5, PR1, PR6, PR1b, Endochitinase, and Beta-1,3glucanase, which are all PRs, were significantly increased in the tomato companied with potato onion compared to the one in the tomato grown alone (Table 4). This was similar to the previous studies, which showed that intercropping could induce the expression of PR genes in a high level (Schmid et al., 2013; Gao et al., 2014). There were some other defenserelated proteins except PRs in plant defense response system, such as Kunitz trypsin inhibitor (Huang et al., 2010), Non-specific lipid-transfer protein (Wang et al., 2004), UDP-glucose salicylic acid glucosyltransferase (Sepúlveda-Jiménez et al., 2005), Wallassociated receptor kinase (Li et al., 2009), Xylanase inhibitor (Sansen et al., 2004), and so on. The genes coding for the proteins were expressed higher in root of tomato grown with potato onion than that in the tomato grown alone (Table 4).

Plant hormones can regulate the expressions of defenserelated genes, especially SA, JA and Ethylene (Wang et al., 2002; Denance et al., 2013). In our study, the expression of genes involved in biosynthesis of Ethylene and response to Ethylene signaling were all up-regulated in tomato companied with potato onion compared to tomato grown alone (Table 5). In terms of SA, 
TABLE 4 | Expression patterns of DEGs related to disease defense.

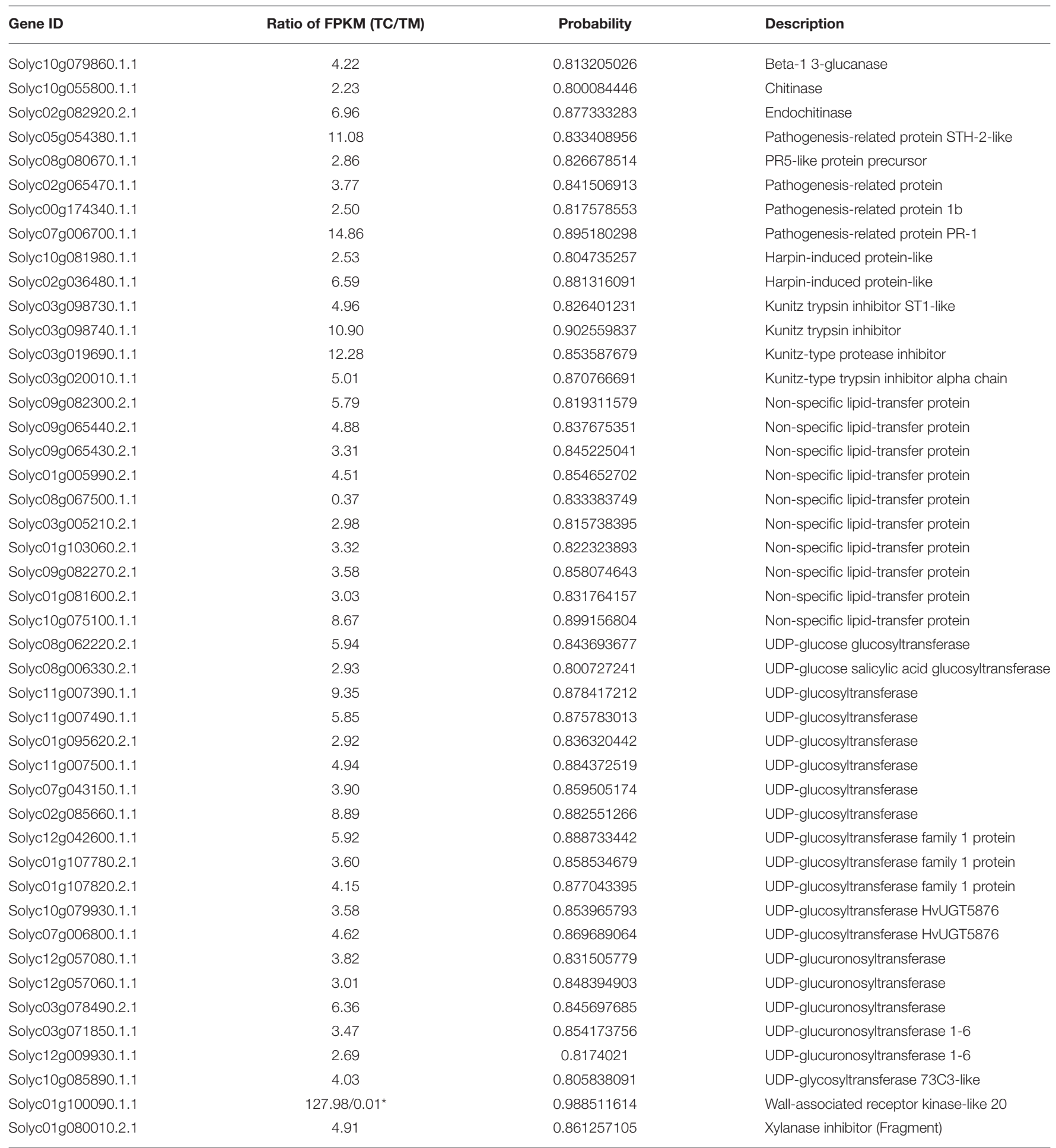

Probability $\geq 0.8$ and the absolute value of Ratio (TC/TM) $\geq 2$ as the threshold to judge the significance of gene expression difference. FPKM represents the expression level. *Indicates the gene was expressed only in TC (when the value of either sample FPKM was zero, 0.01 was used to instead of 0 to calculate the fold change).

the expression of genes involved in SA signaling, such as TGA transcription factor 2 gene, WRKY transcription factor gene and $P R-1$ protein gene were all increased in tomato companied with potato onion (Table 5). These results suggested that Ethylene and SA played important roles in the defense response of tomato against $V$. dahliae. 
TABLE 5 | Expression patterns of DEGs related to hormone metabolism and transcription factors.

\begin{tabular}{|c|c|c|c|}
\hline GenelD & Ratio of FPKM (TC/TM) & Probability & Gene description \\
\hline \multicolumn{4}{|c|}{ HORMONE METABOLISM AND SIGNALING-RELATED GENE EXPRESSION } \\
\hline Solycg049530.2.1 & 5.60 & 0.832236801 & 1-aminocyclopropane-1-carboxylate oxidase \\
\hline Solycg026650.2.1 & 15.26 & 0.819387202 & 1-aminocyclopropane-1-carboxylate oxidase \\
\hline Solyc12g006380.1.1 & 6.18 & 0.891739454 & 1-aminocyclopropane-1-carboxylate oxidase-like protein \\
\hline Solyc09g089580.2.1 & 5.88 & 0.826911685 & 1-aminocyclopropane-1-carboxylate oxidase-like protein \\
\hline Solyc04g009860.2.1 & 3.05 & 0.822418422 & 1-aminocyclopropane-1-carboxylate oxidase-like protein \\
\hline Solyc01g095080.2.1 & 13.46 & 0.894367351 & 1-aminocyclopropane-1-carboxylate synthase \\
\hline Solyc06g053710.2.1 & 4.65 & 0.831587704 & Ethylene receptor \\
\hline Solyc08g014000.2.1 & 0.42 & 0.804476878 & Lipoxygenase \\
\hline Solyc08g029000.2.1 & 3.90 & 0.824378316 & Lipoxygenase \\
\hline Solyc03g122340.2.1 & 4.12 & 0.810173807 & Lipoxygenase \\
\hline Solyc12g013620.1.1 & 4.87 & 0.874434403 & NAC domain protein IPR003441(jasmonic acid 2) \\
\hline Solyc03g071870.1.1 & 20.49 & 0.844008772 & Phenylalanine ammonia-lyase \\
\hline Solyc10g011920.1.1 & 5.99 & 0.863015339 & Phenylalanine ammonia-lyase \\
\hline Solyc10g011930.1.1 & 10.15 & 0.906945967 & Phenylalanine ammonia-lyase \\
\hline Solyc00g282510.1.1 & 7.30 & 0.898564424 & Phenylalanine ammonia-lyase \\
\hline Solyc09g007910.2.1 & 3.38 & 0.814515824 & Phenylalanine ammonia-lyase \\
\hline Solyc08g062220.2.1 & 5.94 & 0.843693677 & UDP-glucose salicylic acid glucosyltransferase \\
\hline Solyc08g006330.2.1 & 2.93 & 0.800727241 & UDP-glucose salicylic acid glucosyltransferase \\
\hline Solyc11g007490.1.1 & 5.85 & 0.875783013 & UDP-glucose salicylic acid glucosyltransferase \\
\hline Solyc11g007500.1.1 & 4.94 & 0.884372519 & UDP-glucose salicylic acid glucosyltransferase \\
\hline Solyc03g078490.2.1 & 6.36 & 0.845697685 & UDP-glucose salicylic acid glucosyltransferase \\
\hline \multicolumn{4}{|c|}{ TRANSCRIPTION FACTORS } \\
\hline Solyc09g005610.2.1 & 9.00 & 0.886849170 & BZIP transcription factor TGA2-like \\
\hline Solyc02g080890.2.1 & 3.09 & 0.829923999 & Transcription factor WRKY31 isoform X1) \\
\hline Solyc02g094270.1.1 & 4.05 & 0.817843234 & WRKY transcription factor 45 \\
\hline Solyc06g066370.2.1 & 2.68 & 0.817320175 & WRKY transcription factor 1 \\
\hline Solycg05g015850.2.1 & 6.76 & 0.846970671 & WRKY transcription factor-b \\
\hline Solyc09g014990.2.1 & 3.13 & 0.803871895 & WRKY-like transcription factor 26 \\
\hline Solyc09g089930.1.1 & 4.32 & 0.816948362 & Ethylene responsive transcription factor 1a \\
\hline Solyc12g056590.1.1 & 3.80 & 0.816948362 & Ethylene responsive transcription factor $2 a$ \\
\hline Solyc04g071770.2.1 & 4.32 & 0.833591712 & Ethylene responsive transcription factor $2 a$ \\
\hline Solyc09g075420.2.1 & 4.61 & 0.864439571 & Ethylene responsive transcription factor $2 \mathrm{~b}$ \\
\hline Solyc09g091950.1.1 & 0.34 & 0.875776711 & Ethylene-responsive transcription factor 1 \\
\hline Solyc02g077370.1.1 & 3.75 & 0.810993055 & Ethylene-responsive transcription factor 2 \\
\hline Solyc01g104740.2.1 & 6.49 & 0.887132756 & Ethylene-responsive transcriptional coactivator \\
\hline Solyc10g008700.1.1 & 6.47 & 0.818990182 & MYB transcription factor \\
\hline Solyc09g090790.2.1 & 4.79 & 0.848502036 & MYB transcription factor \\
\hline Solyc12g099130.1.1 & 6.62 & 0.807974439 & MYB transcription factor \\
\hline Solyc02g089190.1.1 & 8.78 & 0.822746121 & MYB transcription factor \\
\hline Solyc03g093890.2.1 & 4.18 & 0.826130248 & Myb-related transcription factor \\
\hline Solyc02g089190.1.1 & 3.13 & 0.817843234 & Susceptibility homeodomain transcription factor \\
\hline Solyc03g093890.2.1 & 4.00 & 0.830094151 & Sigma factor binding protein 1 \\
\hline Solycg05g054650.1.1 & 4.09 & 0.821567664 & Zinc finger transcription factor ZFP19 \\
\hline Solyc01g096510.2.1 & 2.67 & 0.817206741 & Zinc finger AN1 domain-containing stress-associated protein \\
\hline Solyc02g087210.2.1 & 4.30 & 0.876198939 & Zinc finger family protein $\mathrm{C} 2 \mathrm{H} 2$-type ) \\
\hline Solycg05g054650.1.1 & 4.09 & 0.821567664 & Zinc finger transcription factor ZFP19 \\
\hline
\end{tabular}

Probability $\geq 0.8$ and the absolute value of Ratio $\geq 2$ as the threshold to judge the significance of gene expression difference. FPKM represents the expression level.

The up-regulated expression of genes related to disease response suggested the disease resistance of the tomato companied with potato onion was enhanced compared to that grown alone, in transcriptional level. Together with the decrease of disease development of tomato Verticillium wilt (in morphological level), and induced antifungal activity of 
root exudates from tomato companied with potato onion (in physiological level), the three independent studies demonstrated the disease resistance of tomato was enhanced against $V$. dahliae. This may be a potential mechanism for the management of soil-borne plant diseases in the intercropping system. However, what induced the enhancement of disease resistance of tomato in intercropping was unclear. As Schmid et al., have demonstrated interspecific interactions between Arabidopsis thaliana (plant) and Hieracium pilosella (plant) could highly induce the expression of PR genes (Schmid et al., 2013). Wang et al. observed the changes of activity levels of antioxidases and content of malondialdehyde which were related to stress resistance in the eggplant intercropped with garlic (Wang et al., 2015). These suggested interspecific interactions of plant-plant could induce the resistance response of intercropped plants. But Hage-Ahmed et al., have demonstrated the antifungal activity of root exudates from the tomato was induced by the interactions of plant- AMF- pathogen (Hage-Ahmed et al., 2013). So in our studies, the problem on which the enhancement of disease resistance in tomato root in the intercropping was induced by the interactions of plant (tomato)-plant (potato onion), or by the interactions of plant (tomato)plant (potato onion)-pathogen ( $V$. dahliae) deserved further investigation.

\section{Conclusion}

The results obtained from this study indicated that the companion cropping with potato onion could decrease the incidence of tomato Verticillium wilt and alleviate the disease severity levels. The further study showed the tomato companied with potato onion was induced to produce antifungal activity

\section{References}

Bai, T. T., Xie, W. B., Zhou, P. P., Wu, Z. L., Xiao, W. C., Zhou, L., et al. (2013). Transcriptome and expression profile analysis of highly resistant and susceptible banana roots challenged with Fusarium oxysporum f.sp. cubense tropical race 4. PLoS ONE 8:e73945. doi: 10.1371/journal.pone.0073945

Boudreau, M. A. (2013). Diseases in intercropping systems. Annu. Rev. Phytopathol. 51, 499-519. doi: 10.1146/annurev-phyto-082712102246

Chisholm, S. T., Coaker, G., Day, B., and Staskawicz, B. J. (2006). Host-microbe interactions: shaping the evolution of the plant immune response. Cell 124, 803-814. doi: 10.1016/j.cell.2006.02.008

Denance, N., Sanchez-Vallet, A., Goffner, D., and Molina, A. (2013). Disease resistance or growth: the role of plant hormones in balancing immune responses and fitness costs. Front. Plant Sci. 4:155. doi: 10.3389/fpls.2013. 00155

Dobinson, K., Tenuta, G., and Lazarovits, G. (1996). Occurrence of race 2 of Verticillium dahliae in processing tomato fields in southwestern Ontario. Can. J. Plant Pathol. 18, 55-58. doi: 10.1080/07060669609500655

Fengzhi, W., and Xingang, Z. (2009). Effect of intercropping of cucumber with different crops on cucumber diseases and soil microbial community diversity. Acta Pedologica Sinica 46, 899-906.

Gao, X., Wu, M., Xu, R., Wang, X., Pan, R., Kim, H. J., et al. (2014). Root interactions in a maize/soybean intercropping system control soybean soil-borne disease, red crown rot. PLOS ONE 9:e95031. doi: 10.1371/journal.pone.0095031 for the inhibition of $V$. dahliae growth via root exudates under the condition of infection with $V$. dahliae. Meanwhile, the expressions of genes related to disease resistance were higher in tomato companied with potato onion compared to those in tomato grown alone. Based on the results, we proposed that companion cropping with potato onion enhance the disease resistance of tomato against $V$. dahliae, by inducing the antifungal activity of root exudates from tomato, and by the up-regulated expression of genes involved in defense response to pathogen. This may be a potential mechanism for the management of tomato Verticillium wilt in tomato/potato onion companion cropping.

\section{Acknowledgments}

This research was supported by the National Natural Science Foundation of China (project No. 31172002) and National Staple Vegetable Industrial Technology Systems of China (CARS-2508). We would like to thank those agencies of the People's Republic of China for financing the project. We would like to thank Dr. Xiangyang Xu (Tomato Breeding Center of Northeast Agricultural University) for providing us with Verticillium dahliae race 1 (Vd1), and Dr. Kui Chen (Abbott Laboratories) for the revision of our manuscript.

\section{Supplementary Material}

The Supplementary Material for this article can be found online at: http://journal.frontiersin.org/article/10.3389/fpls.2015. 00726
Gómez-Rodriguez, O., Zavaleta-Mejıa, E., Gonzalez-Hernandez, V., LiveraMunoz, M., and Cárdenas-Soriano, E. (2003). Allelopathy and microclimatic modification of intercropping with marigold on tomato early blight disease development. Field Crops Res. 83, 27-34. doi: 10.1016/S0378-4290(03) 00053-4

Hage-Ahmed, K., Moyses, A., Voglgruber, A., Hadacek, F., and Steinkellner, S. (2013). Alterations in root exudation of intercropped tomato mediated by the arbuscular mycorrhizal fungus Glomus mosseae and the soilborne pathogen Fusarium oxysporum f.sp. lycopersici. J. Phytopathol. 161, 763-773. doi: $10.1111 /$ jph.12130

Hao, W. Y., Ren, L. X., Ran, W., and Shen, Q. R. (2010).Allelopathic effects of root exudates from watermelon and rice plants on Fusarium oxysporum f.sp. niveum. Plant Soil 336, 485-497. doi: 10.1007/s11104-010-0505-0

Huang, H., Qi, S. D., Qi, F., Wu, C. A., Yang, G. D., and Zheng, C. C. (2010) NtKTI1, a Kunitz trypsin inhibitor with antifungal activity from Nicotiana tabacum, plays an important role in tobacco's defense response. FEBS J. 277, 4076-4088. doi: 10.1111/j.1742-4658.2010.07803.x

Kanehisa, M., Araki, M., Goto, S., Hattori, M., Hirakawa, M., Itoh, M., et al. (2008). KEGG for linking genomes to life and the environment. Nucleic Acids Res. 36, D480-D484. doi: 10.1093/nar/gkm882

Klosterman, S. J., Atallah, Z. K., Vallad, G. E., and Subbarao, K. V. (2009). Diversity, pathogenicity, and management of Verticillium species. Ann. Rev. Phytopathol. 47, 39-62. doi: 10.1146/annurev-phyto-080508-081748

Langmead, B., Trapnell, C., Pop, M., and Salzberg, S. L. (2009). Ultrafast and memory-efficient alignment of short DNA sequences to the human genome. Genome Biol. 10:R25. doi: 10.1186/gb-2009-10-3-r25 
Li, B., and Dewey, C. N. (2011). RSEM: accurate transcript quantification from RNA-Seq data with or without a reference genome. BMC Bioinformatics 12:323. doi: 10.1186/1471-2105-12-323

Li, H., and Durbin, R. (2009). Fast and accurate short read alignment with Burrows-Wheeler transform. Bioinformatics 25, 1754-1760. doi: 10.1093/bioinformatics/btp324

Li, H., Zhou, S. Y., Zhao, W. S., Su, S. C., and Peng, Y. L. (2009). A novel wallassociated receptor-like protein kinase gene, OsWAK1, plays important roles in rice blast disease resistance. Plant Mol. Biol. 69, 337-346. doi: 10.1007/s11103008-9430-5

Li, L., Tilman, D., Lambers, H., and Zhang, F. S. (2014). Plant diversity and overyielding: insights from belowground facilitation of intercropping in agriculture. New Phytol. 203, 63-69. doi: 10.1111/nph.12778

Li, X. G., Zhang, T. L., Wang, X. X., Hua, K., Zhao, L., and Han, Z. M. (2013). The composition of root exudates from two different resistant peanut cultivars and their effects on the growth of soil-borne pathogen. Int. J. Biol. Sci. 9, 164-173. doi: 10.7150/ijbs.5579

Liu, S. Q., Wu, F. Z., and Wen, X. Y. (2013). Allelopathic effects of root exudates of Chinese onion on tomato growth and the pathogen Fusarium oxysporum(Sch1) f.sp. lycopersici. Allelopathy J. 31, 387-404.

Løvdal, T., and Lillo, C. (2009). Reference gene selection for quantitative real-time PCR normalization in tomato subjected to nitrogen, cold, and light stress. Anal. Biochem. 387, 238-242. doi: 10.1016/j.ab.2009.01.024

Lü, G., Guo, S., Zhang, H., Geng, L., Song, F., Fei, Z., et al. (2011). Transcriptional profiling of watermelon during its incompatible interaction with Fusarium oxysporum f.sp. niveum. Eur. J. Plant Pathol. 131, 585-601. doi: 10.1007/s10658-011-9833-Z

Orenstein, J., Nachmias, A., and Lips, H. (1989). Inhibition of tomato root growth in culture by a Verticillium dahliae phytotoxin. Phytoparasitica 17, 269-278. doi: 10.1007/BF02980756

Pegg, G., and Street, P. (1984). Measurement of Verticillium albo-atrum in high and low resistance hop cultivars. Trans. Br. Mycol. Soc. 82, 99-106. doi: 10.1016/S0007-1536(84)80216-8

Ratnadass, A., Fernandes, P., Avelino, J., and Habib, R. (2012). Plant species diversity for sustainable management of crop pests and diseases in agroecosystems: a review. Agron. Sust. Dev. 32, 273-303. doi: 10.1007/s13593011-0022-4

Ren, L., Su, S., Yang, X., Xu, Y., Huang, Q., and Shen, Q. (2008). Intercropping with aerobic rice suppressed Fusarium wilt in watermelon. Soil Biol. Biochem. 40, 834-844. doi: 10.1016/j.soilbio.2007.11.003

Robb, J., Castroverde, C. D., Shittu, H. O., and Nazar, R. N. (2009). Patterns of defence gene expression in the tomato-Verticillium interaction. Botany 87, 993-1006. doi: 10.1139/B09-056

Sansen, S., De Ranter, C. J., Gebruers, K., Brijs, K., Courtin, C. M., Delcour, J. A., et al. (2004). Structural basis for inhibition of Aspergillus niger xylanase by Triticum aestivum xylanase inhibitor-I. J. Biol. Chem. 279, 36022-36028. doi: 10.1074/jbc.M404212200

Schmid, C., Bauer, S., Müller, B., and Bartelheimer, M. (2013). Belowground neighbor perception in Arabidopsis thaliana studied by transcriptome analysis: roots of Hieracium pilosella cause biotic stress. Front. Plant Sci. 4:296. doi: 10.3389/fpls.2013.00296

Sepúlveda-Jiménez, G., Rueda-Benítez, P., Porta, H., and Rocha-Sosa, M. (2005). A red beet (Beta vulgaris) UDP-glucosyltransferase gene induced by wounding, bacterial infiltration and oxidative stress. J. Exp. Bot. 56, 605-611. doi: $10.1093 /$ jxb/eri036

Shamrai, S. N. (2014). Plant immune system: basal immunity. Cytol. Genet. 48, 258-271. doi: 10.3103/S0095452714040057
Shittu, H. O., Castroverde, D. C., Nazar, R. N., and Robb, J. (2009). Plantendophyte interplay protects tomato against a virulent Verticillium. Planta 229, 415-426. doi: 10.1007/s00425-008-0840-z

Tarazona, S., García-Alcalde, F., Dopazo, J., Ferrer, A., and Conesa, A. (2011). Differential expression in RNA-seq: a matter of depth. Genome Res. 21, 2213-2223. doi: 10.1101/gr.124321.111

Underwood, W. (2012). The plant cell wall: a dynamic barrier against pathogen invasion. Front. Plant Sci. 3:85. doi: 10.3389/fpls.2012.00085

van Loon, L. C., Rep, M., and Pieterse, C. (2006). Significance of inducible defenserelated proteins in infected plants. Annu. Rev. Phytopathol. 44, 135-162. doi: 10.1146/annurev.phyto.44.070505.143425

van Wees, S. C., de Swart, E. A., van Pelt, J. A., van Loon, L. C., and Pieterse, C. M. (2000). Enhancement of induced disease resistance by simultaneous activation of salicylate-and jasmonate-dependent defense pathways in Arabidopsis thaliana. Proc. Nat. Acad. Sci. U.S.A. 97, 8711-8716. doi: $10.1073 /$ pnas. 130425197

Wang, K. L. C., Li, H., and Ecker, J. R. (2002). Ethylene biosynthesis and signaling networks. Plant Cell 14, S131-S151. doi: 10.1105/tpc.001768

Wang, M. Y., Wu, C. N., Cheng, Z. H., and Meng, H. W. (2015). Growth and physiological changes in continuously cropped eggplant (Solanum melongena L.) upon relay intercropping with garlic (Allium sativum L.). Front. Plant Sci. 6:262. doi: 10.3389/fpls.2015.00262

Wang, S. Y., Wu, J. H., Ng, T. B., Ye, X. Y., and Rao, P. F. (2004). A non-specific lipid transfer protein with antifungal and antibacterial activities from the mung bean. Peptides 25, 1235-1242. doi: 10.1016/j.peptides.2004.06.004

Xu, L. N., Wang, Y. Q., Wang, Z. Y., Hu, B. J., Ling, Y. H., and He, K. L. (2015b). Transcriptome differences between CrylAb resistant and susceptible strains of Asian corn borer. BMC Genomics 16:173. doi: 10.1186/s12864-015-1362-2

Xu, W., Liu, D., Wu, F., and Liu, S. (2015a). Root exudates of wheat are involved in suppression of Fusarium wilt in watermelon in watermelon-wheat companion cropping. Eur. J. Plant Pathol. 141, 209-216. doi: 10.1007/s10658-0140528-0

Yang, M., Zhang, Y., Qi, L., Mei, X., Liao, J., Ding, X., et al. (2014). Plantplant-microbe mechanisms involved in soil-borne disease suppression on a maize and pepper intercropping system. PLoS ONE 9:e115052. doi: 10.1371/journal.pone.0115052

Yang, Y. X., Wang, M. M., Yin, Y. L., Onac, E., Zhou, G. F., Peng, S., et al. (2015). RNA-seq analysis reveals the role of red light in resistance against Pseudomonas syringae pv. tomato DC3000 in tomato plants. BMC Genomics 16:120. doi: 10.1186/s12864-015-1228-7

Ye, J., Fang, L., Zheng, H. K., Zhang, Y., Chen, J., Zhang, Z. J., et al. (2006). WEGO: a web tool for plotting GO annotations. Nucleic Acids Res. 34, W293-W297. doi: 10.1093/nar/gkl031

Zheng, X. M., and Moriyama, E. N. (2013). Comparative studies of differential gene calling using RNA-Seq data. BMC Bioinformatics 14:S7. doi: 10.1186/14712105-14-S13-S7

Conflict of Interest Statement: The authors declare that the research was conducted in the absence of any commercial or financial relationships that could be construed as a potential conflict of interest.

Copyright (c) $2015 \mathrm{Fu}, \mathrm{Wu}, \mathrm{Zhou}, \mathrm{Liu}$, Shen and Wu. This is an open-access article distributed under the terms of the Creative Commons Attribution License (CC BY). The use, distribution or reproduction in other forums is permitted, provided the original author(s) or licensor are credited and that the original publication in this journal is cited, in accordance with accepted academic practice. No use, distribution or reproduction is permitted which does not comply with these terms. 